Check for updates

Cite this: RSC Adv., 2019, 9, 32839

Received 19th July 2019

Accepted 17th September 2019

DOI: $10.1039 / c 9 r a 05587 h$

rsc.li/rsc-advances

\section{A rapid on-site analysis method for the simultaneous extraction and determination of $\mathrm{Pb}^{2+}$ and $\mathrm{Cd}^{2+}$ in cereals $\uparrow$}

\author{
Ming-hui Zhou, $\$$ Wei Tian, $\$$ Jie-qiong Zhang, Xi Chen, Yan-xiang Wu \\ and Song-xue Wang (iD *
}

In order to achieve rapid on-site screening and solve the problem of rapid pretreatment for the determination of lead $\left(\mathrm{Pb}^{2+}\right)$ and cadmium $\left(\mathrm{Cd}^{2+}\right)$ in cereals by a portable electrochemical analyzer with disposable screen-printed electrodes (SPEs), a new reliable and simple extraction method for $\mathrm{Pb}^{2+}$ and $\mathrm{Cd}^{2+}$ in cereals was developed. The $\mathrm{Pb}^{2+}$ and $\mathrm{Cd}^{2+}$ in cereals were purified by a mixed solution of $1 \mathrm{~mol} \mathrm{~L} \mathrm{~L}^{-1}$ potassium iodide $(\mathrm{KI}) / 5 \%$ vitamin $\mathrm{C}(\mathrm{VC}) /$ ethyl acetate after being extracted by $10 \% \mathrm{HNO}_{3}$, which transfers the $\mathrm{Pb}^{2+}$ and $\mathrm{Cd}^{2+}$ into ethyl acetate after a reaction with $\mathrm{KI}-\mathrm{VC}$. Then, the $\mathrm{Pb}^{2+}$ and $\mathrm{Cd}^{2+}$ were eluted from ethyl acetate with $5 \% \mathrm{HNO}_{3}$ and were determined by an electrochemical analyzer with screen printed electrodes. Under the optimized conditions, the matrix calibration curves of $\mathrm{Pb}^{2+}$ and $\mathrm{Cd}^{2+}$ in rice and wheat showed good linear relationships with $R^{2}>0.996$. The method shows a detection limit (LOD) for $\mathrm{Cd}^{2+}$ in rice and wheat of $6.7 \mu \mathrm{g} \mathrm{kg}^{-1}$ and $11.5 \mathrm{\mu g} \mathrm{kg}^{-1}$, and the corresponding values for $\mathrm{Pb}^{2+}$ were 34.9 and $31.1 \mu \mathrm{g} \mathrm{kg}^{-1}$, respectively. The relative standard deviation (RSD) was less than $8.7 \%$ for $\mathrm{Cd}^{2+}$ and $\mathrm{Pb}^{2+}$. In addition, the recoveries of the tested reference materials using this method were between $80 \%$ and $120 \%$. From sample pretreatment to testing results, the whole process took no more than $25 \mathrm{~min}$, and the operation was simple for operators, green to the environment, cheap in terms of instruments, and above all suitable for on-site detection. The results implied that this portable electrochemical method with new pretreatment may be a good choice for screening $\mathrm{Pb}^{2+}$ and $\mathrm{Cd}^{2+}$ in cereal samples on-site.

\section{Introduction}

Heavy metals are known to pose a great threat not only to human beings, but also to aquatic plants and animals, due to their high toxicity, high stability and non-biodegradability. ${ }^{1}$ In particular, the two major pollutants $\mathrm{Pb}^{2+}$ and $\mathrm{Cd}^{2+}$ easily pose an acute or chronic risk even at low concentrations, causing headaches, hypertension, skeletal malformation in fetuses, arthralgia, renal damage and so on. ${ }^{2,3}$ Most of the $\mathrm{Pb}^{2+}$ and $\mathrm{Cd}^{2+}$ is generated from industry and then released into water and soil, continuously transferred into plants, and accumulated in cereals and humans. ${ }^{4}$ What's more, cereals are the main food crop for half of the world's population. ${ }^{5}$ This mode of diet has greatly increased people's intake of heavy metals and the risk of disease. Therefore, on account of the harmfulness and scattered samples, rapid and on-site detection methods are extremely

The Academy of National Food and Strategic Reserves Administration (Former Name: Academy of State Administration of Grain, ab. ASAG), No. 11 Baiwanzhuang Str., Xicheng District, Beijing 100037, China. E-mail: wsx@chinagrain.org

$\dagger$ Electronic supplementary information (ESI) available. See DOI: 10.1039/c9ra05587h

\$ These authors contributed equally to this work. urgent, and it is of great importance for human health to detect $\mathrm{Pb}^{2+}$ and $\mathrm{Cd}^{2+}$ in a quick and reliable way. ${ }^{6}$ Especially in countries where rice production has not realized intensive cultivation, such as China, the problem of $\mathrm{Pb}^{2+}$ and $\mathrm{Cd}^{2+}$ in cereals is salient.

However, there are still some difficulties in realizing the rapid detection of $\mathrm{Pb}^{2+}$ and $\mathrm{Cd}^{2+}$ in grains on-site. Over the past few decades, there has been increasing interest in the development of detection methods for $\mathrm{Pb}^{2+}$ and $\mathrm{Cd}^{2+}$. Routine methods for detection are atomic absorption spectroscopy (AAS), ${ }^{7}$ inductively coupled plasma-mass spectrometry (ICPMS), ${ }^{8}$ inductively coupled plasma atomic emission spectrometry (ICP-AES), ${ }^{9}$ and inductively coupled plasma-optical emission spectrometry (ICP-OES) ${ }^{10}$ and so on. These methods have achieved high precision for detecting heavy metal ions, but they have some disadvantages, such as the high cost of the cumbersome instruments required and their maintenance, the requirement of skilled professionals and being timeconsuming. ${ }^{11,12}$ These drawbacks have limited their application in the field. Therefore, it is imperative to establish portable analytical systems.

Electrochemical methods, in particular based on screen printed electrodes (SPEs), are widely used in heavy metal ion 
detection due to their low cost, simple operation and fast response. ${ }^{13-15}$ Since the 1990s, screen-printed technology has been used for electrochemical sensors, ${ }^{\mathbf{1 6}}$ which are generally used in many fields, especially for water detection. However, they are rarely used in cereal samples because of the complicated matrix interference. Complex matrices of samples, involving proteins, fats, pigments and other ions, can result in a significant gap between the lab value and on-site measurement conditions. ${ }^{17}$ Therefore, complicated matrix interference, low concentrations of heavy metal ions and high levels of electrolyte background are key challenges for the electrochemical measurement performance. ${ }^{18}$ The way to solve these problems partly depends on pretreatment. The traditional digestion method requires a lot of strong acid and it takes a long time (at least 2-3 hours). ${ }^{19}$ Recently, a method which uses diluted acid for extracting $\mathrm{Cd}^{2+}$ and $\mathrm{Pb}^{2+}$ has been developed for the purpose of abandoning the dangerous strong acid and simplifying the operations. ${ }^{20-22}$ What's more, some researchers have also applied 4-methyl-2-pentanone (MIBK) in pretreatment for further purification. Most of the publications employing MIBK as the solvent extractor focused on pretreatment prior to $\mathrm{Cd}^{2+}$ and $\mathrm{Pb}^{2+}$ analysis, where it was used widely for water and soil. Compared to traditional pretreatment, this method indeed saved a lot of time, but there are only a few reports on the determination of $\mathrm{Pb}^{2+}$ and $\mathrm{Cd}^{2+}$ in cereal samples using MIBK extraction methods. Shi et $a .^{23}$ used ammonium pyrroline dithiocarbamate (APDC) to coordinate metal ions and then extracted them with MIBK, and the final results complied with the requirements of neutron activation analysis (NAA). Xin et $a .^{24}$ used KI to perform a substitution reaction with $\mathrm{Pb}^{2+}$ and $\mathrm{Cd}^{2+}$ before they were extracted with MIBK. In fact, MIBK is currently a relatively hard-to-get chemical intermediate, and it is considered to be a hazardous air pollutant, especially in highrise air, ${ }^{25}$ but other common solvents have been rarely studied to replace MIBK. Ethyl acetate is a good alternative to organic solvents because of its non-toxic and excellent properties for extraction. But regarding $\mathrm{KI}$-ethyl acetate extraction for an effective cereal pretreatment method, there has been no report yet.

In this study, we developed a rapid pretreatment approach coupled with an electrochemical method to determine trace $\mathrm{Pb}^{2+}$ and $\mathrm{Cd}^{2+}$ simultaneously in cereal samples (rice and wheat) with a portable heavy metal screen-printed electrode. In brief, the target $\mathrm{Pb}^{2+}$ and $\mathrm{Cd}^{2+}$ were simultaneously extracted by diluted acid from cereals, and the ions reacted with organic acids (vitamin $\mathrm{C}$ ) and potassium iodide to form the associated complexes, which can be transferred to the organic phase and then eluted into inorganic acids. After a simple pretreatment of the samples, the on-site analysis was carried out using disposable screen printed electrodes as the working electrodes. Some of the key factors, such as the extraction rate, elimination of interferences and electrode working conditions, were investigated. Moreover, the analytical performance of this method was validated with certified reference materials in comparison with the ICP-MS method. Under the optimal parameters, the basic standard curve was established. The detection limits, repeatability, and accuracy were all evaluated. In the meantime, real cereal samples collected from markets were used to demonstrate the reliability of the new method in comparison with ICPMS. The whole detection procedure took less than $25 \mathrm{~min}$, and it supplied a reliable method for the simultaneous detection of $\mathrm{Pb}^{2+}$ and $\mathrm{Cd}^{2+}$ in cereals on site.

\section{Experimental}

\section{Chemicals}

All certified reference materials (CRMs), namely GBW(E)100350, GBW(E)100348, GBW100361, GBW100378, and GBW100379, were purchased from the National Institute of Metrology, China. ZK012, ZK014, ZK004, ZK001, ZK002, ZK003, FD, FM and other samples containing $\mathrm{Cd}^{2+}$ and $\mathrm{Pb}^{2+}$ were prepared by the Academy of National Food and Strategic Reserves Administration, China. $\mathrm{HNO}_{3}$, ammonium acetate and $\mathrm{KI}$ were purchased from Beijing Chemical Reagent Research Institute. VC was purchased from CNW technologies. Ethyl acetate (GR) was purchased from Fisher Chemical. $\mathrm{Pb}^{2+}$ and $\mathrm{Cd}^{2+}$ standard solutions were purchased from National Institute of Metrology. Electrolyte buffer solutions were kindly provided by Wuhan Zhongkezhikang Biotechnology Co. Ltd.

\section{Instruments}

All solutions were prepared with ultrapure water (resistivity: 18.2 $\mathrm{M} \Omega \mathrm{cm}^{-1}$ ) from a Milli-Q purification system (USA), and the samples were ground in a grinder (Fritsch, Germany). $\mathrm{Cd}^{2+}$ and $\mathrm{Pb}^{2+}$ in the extracts was quantified by ICP-MS (7500CX, Agilent, USA). A high-speed centrifuge (3-30KS, Sigma Laborzentrifugen Gmbh, Germany) was used to separate the extracted solutions. The screen printed graphite working electrodes (SPEs) and the electrochemical detector were kindly provided by Wuhan Zhongkezhikang Biotechnology Co. Ltd.

\section{Cereal sample preparation}

In this study, rice and wheat were selected as the representative samples due to them being the most prevalent cereals as a staple food worldwide and the fact that they are commonly regarded as cereals in which heavy metals are easily accumulated. Unlike the simple diluted acid extraction, ${ }^{26}$ the new method could get rid of more soluble impurities. Briefly, the samples were ground into a powder and mixed completely. A portion $(0.25 \mathrm{~g})$ was transferred into an extraction tube, and the following solutions were added to the tube in sequence: $10 \%$ $\mathrm{HNO}_{3}, 10 \% \mathrm{VC}$ solution, $2 \mathrm{~mol} \mathrm{~L}^{-1} \mathrm{KI}$ solution, and ethyl acetate. The $\mathrm{Pb}^{2+}$ and $\mathrm{Cd}^{2+}$ were extracted and cleaned from this mixture solution by vigorously vortexing for $10 \mathrm{~min}$ on a shaker. After being centrifuged at $4000 \mathrm{rpm}$ for $5 \mathrm{~min}$, the solvent was separated from the aqueous layer. Then, a $1 \mathrm{~mL}$ aliquot of the ethyl acetate supernatant was back-extracted with $5 \% \mathrm{HNO}_{3}$ by hand-shaking for $1 \mathrm{~min}$. After stratification, the organic solvent was abandoned and the aqueous phase was prepared for detection. 


\section{Procedure of the electrochemical method of $\mathrm{Pb}^{2+}$ and $\mathrm{Cd}^{2+}$}

The analysis of $\mathrm{Pb}^{2+}$ and $\mathrm{Cd}^{2+}$ by the one-strip electrochemical method with solvent extraction was performed in acetate buffer solutions. The SPEs had three electrodes, consisting of a round carbon working electrode (diameter of $2.8 \mathrm{~mm}$ ), a carbon auxiliary electrode, and a silver pseudo-reference electrode. The working electrode should be activated first. In brief, under stirring conditions, the electrode was immersed in a mixture buffer containing $1 \mathrm{~mL}$ of $0.5 \mathrm{~mol} \mathrm{~L}^{-1}$ acetate buffer solution and $40 \mu \mathrm{L}$ of $1000 \mathrm{mg} \mathrm{L} \mathrm{L}^{-1} \mathrm{Hg}^{+}$standard solution and the deposition potential $(-1.3 \mathrm{~V})$ was applied to the working electrode for $200 \mathrm{~s}$. This step was to activate the electrode and form an amalgam on the surface of the electrode, which can improve the sensitivity and stability. After the electrode was activated, $200 \mu \mathrm{L}$ of sample solution was added to the sample cell that already contained the activated electrode scanned for $200 \mathrm{~s}$ and a potential scan was carried out from $-1.3 \mathrm{~V}$ to $0.6 \mathrm{~V}$. After an equilibration period, the potential scan was carried out for $10 \mathrm{~s}$, and the solution was not stirred in this step. The parameters of the detection conditions were set up, such as frequency $(10 \mathrm{~Hz})$, amplitude $(25 \mathrm{mV})$ and scan rate $\left(4 \mathrm{mV} \mathrm{s}^{-1}\right)$. All the steps were imposed at room temperature. The main principle and processes are shown in Fig. 1.

\section{Optimization of the working conditions and matrix-matched calibration curves}

In this method, one of the priority issues of the whole detection was the sample extraction procedure, and it was of great importance to extract and concentrate the target metal ions from the cereal samples. In order to obtain a complete extraction rate, the following critical factors were studied, such as the nitric acid concentration, the ratio of sample to diluted-nitric acid $(\mathrm{m} / \mathrm{v})$, the extraction pattern and extraction time, and the concentration of KI and VC. Under the optimized working conditions, calibration curves were established. A series of standard cereal materials that contained different

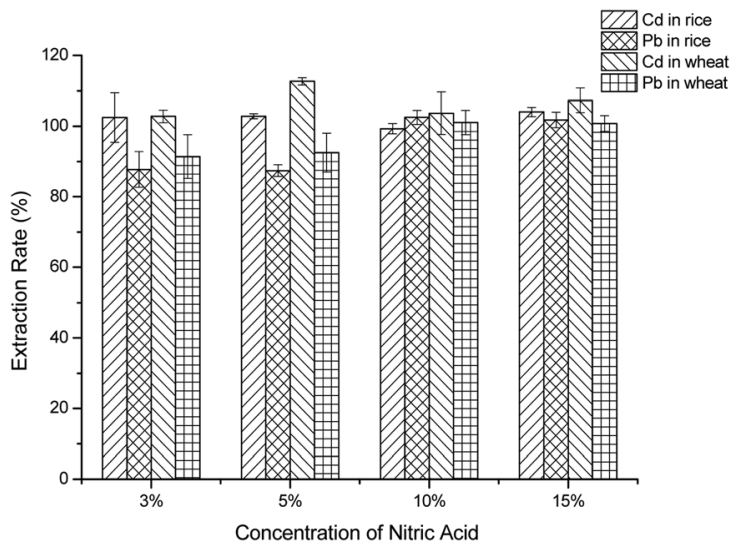

Fig. 2 The effect of the concentration of nitric acid.

concentrations of $\mathrm{Pb}^{2+}$ and $\mathrm{Cd}^{2+}$ were chosen as the standard matrixes, and calibration curves were evaluated by plotting the current response against concentration. The limit of detection (LOD) $(3 \sigma / s)$ and the limit of quantification (LOQ) $(10 \sigma / s)$ were also calculated from the calibrations, where $\sigma$ is the standard deviation of eleven blank measurements and $s$ is the slope of the calibration curve.

For optimization of the nitric acid concentration, in this part, $3 \%, 5 \%, 10 \%$ and $15 \% \mathrm{HNO}_{3}$ were studied for the extraction rate of $\mathrm{Pb}^{2+}$ and $\mathrm{Cd}^{2+}$. Different concentrations of acid were added to the certified reference samples, and the operation was carried out according to "Cereal sample preparation" and "Procedure of the electrochemical method of $\mathrm{Pb}^{2+}$ and $C d^{2+}$. The recoveries of $\mathrm{Pb}^{2+}$ and $\mathrm{Cd}^{2+}$ were calculated.

For optimization of the ratio of sample to diluted-nitric acid $(\mathrm{m} / \mathrm{v})$, the ratios of sample to diluted-nitric acid $(\mathrm{m} / \mathrm{v})$ were set as $1: 5,1: 10$ and $1: 15$. Through the steps mentioned above in "Cereal sample preparation", the untested liquid was detected. The recoveries of $\mathrm{Pb}^{2+}$ and $\mathrm{Cd}^{2+}$ were calculated.

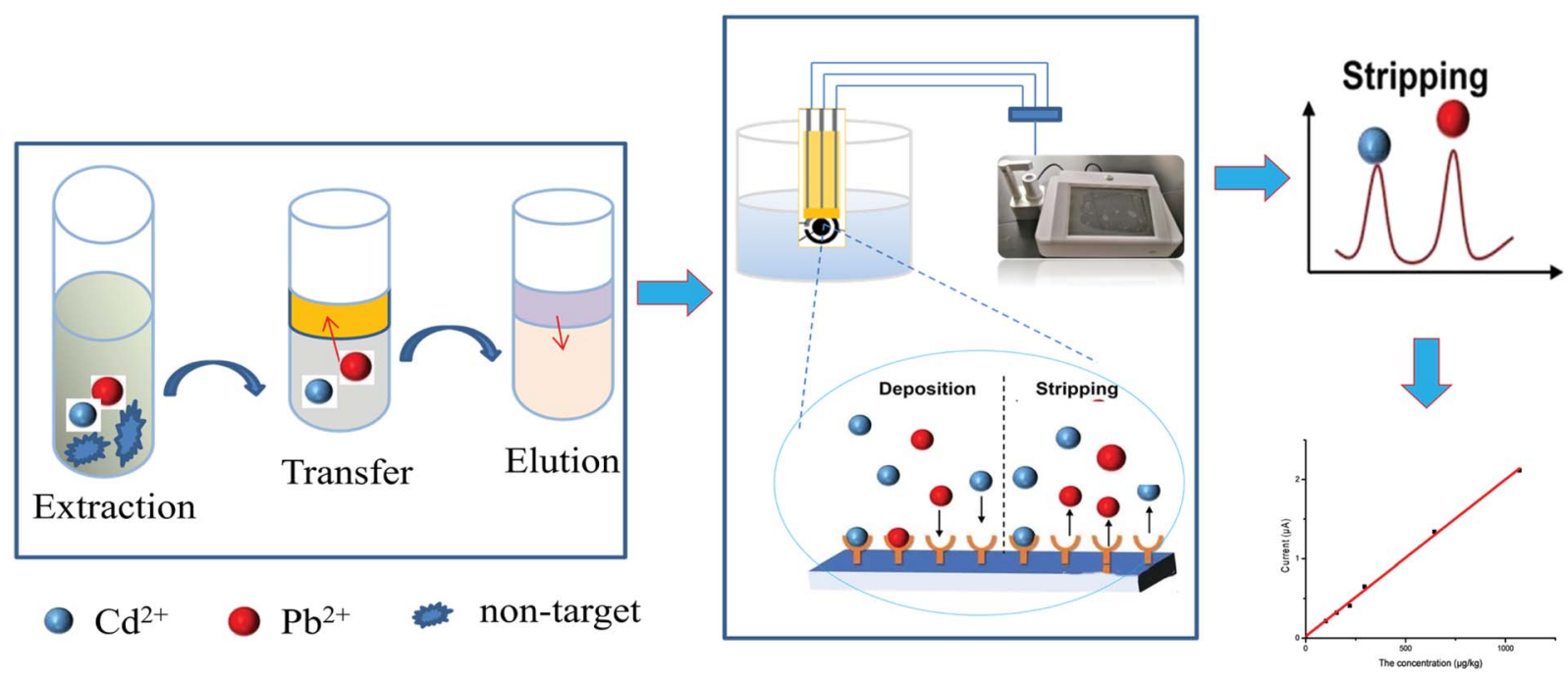

Fig. 1 The principle of the portable electrochemical method. 


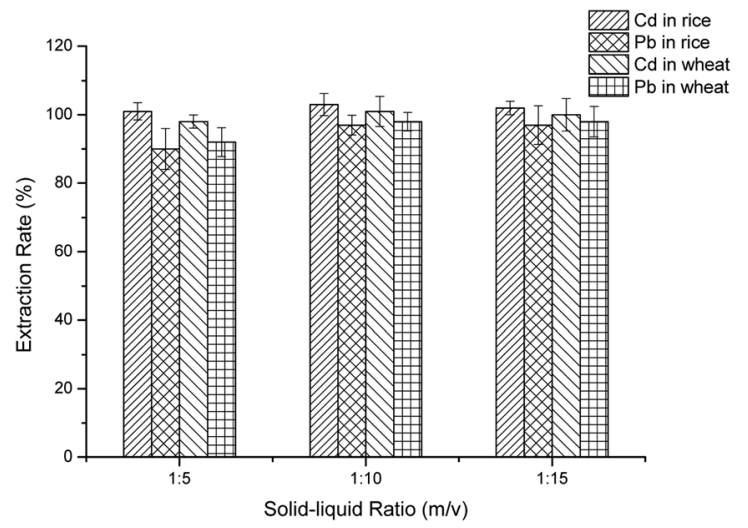

Fig. 3 The effect of the solid to liquid ratio for extraction.

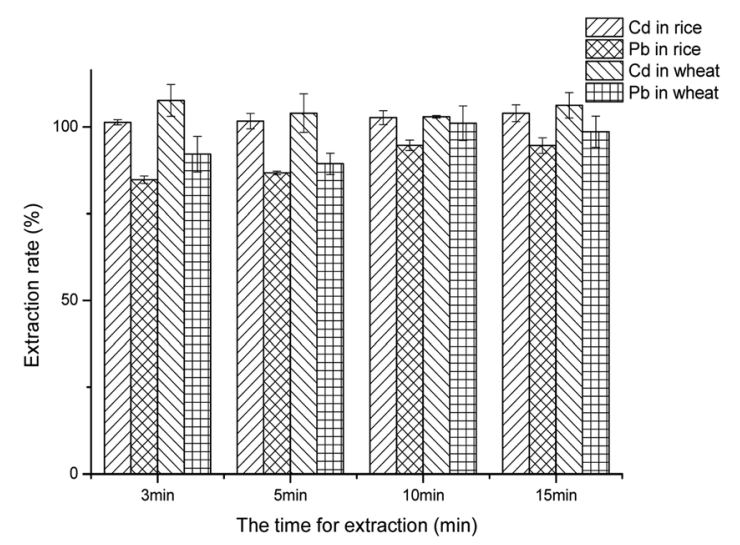

Fig. 4 The effect of the extraction time.

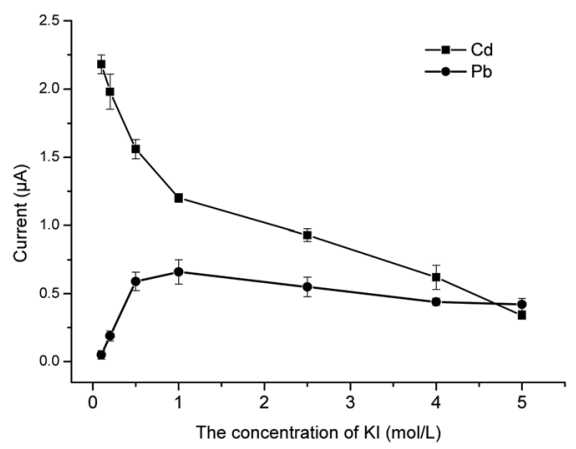

Fig. 5 The effect of the concentration of Kl.

For optimization of the extraction time and the extraction method, to improve the extraction rate, the best extraction time and method were evaluated; the extraction time was $3,5,10$, or $15 \mathrm{~min}$, and at each time, two extraction methods, namely shaking and vortexing, were used to extract $\mathrm{Cd}^{2+}$ and $\mathrm{Pb}^{2+}$ in both rice and wheat.

For optimization of the concentration of KI, to identify the influence of KI on the method, different concentrations of KI solution $\left(0.1,0.2,0.5,1.0,2.5,4.0,5.0 \mathrm{~mol} \mathrm{~L}^{-1}\right)$ were added

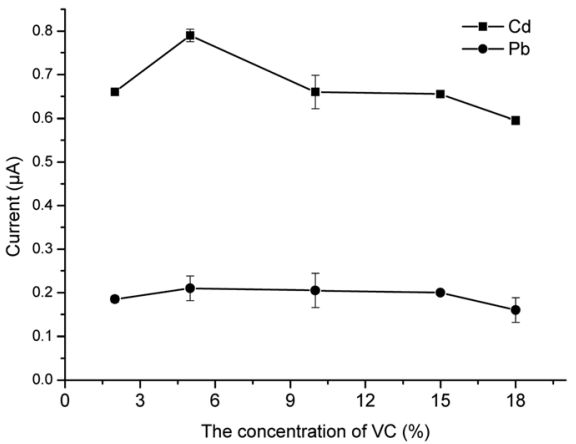

Fig. 6 The effect of the concentration of VC.

Table 1 Study on the concentration of eluent

\begin{tabular}{llllll}
\hline & \multicolumn{2}{l}{$\begin{array}{l}\text { The current of rice } \\
(\mu \mathrm{A})\end{array}$} & & \multicolumn{2}{l}{$\begin{array}{l}\text { The current of } \\
\text { wheat }(\mu \mathrm{A})\end{array}$} \\
\cline { 2 - 3 } & $\mathrm{Cd}$ & $\mathrm{Pb}$ & & $\mathrm{Cd}$ & $\mathrm{Pb}$ \\
\cline { 2 - 3 } Eluent & 1.09 & 0.36 & & 0.83 & 0.47 \\
\hline $5 \% \mathrm{HNO}_{3}$ & 0.62 & 0.33 & & 0.63 & 0.47
\end{tabular}

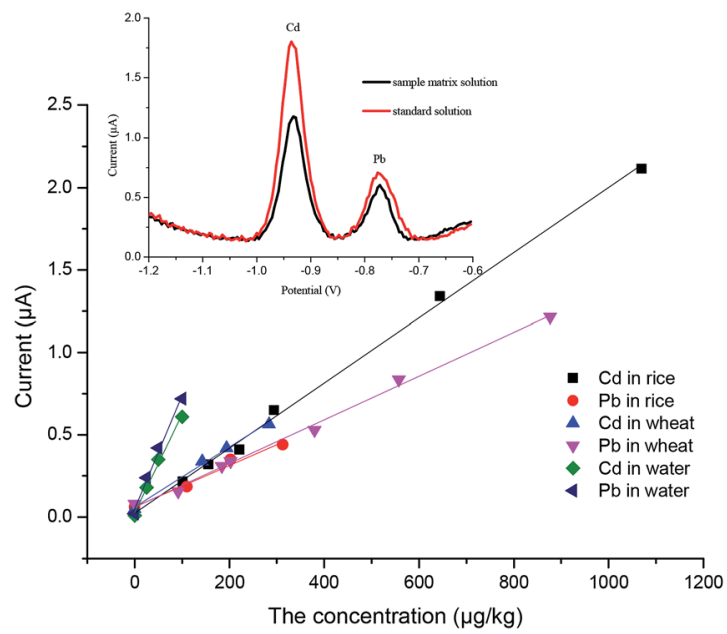

Fig. 7 Comparison and analysis of calibration curves of the standard solution and sample solution. Inset: square-wave stripping voltammograms at the SPEs for concentration levels of $\mathrm{Cd}^{2+}$ and $\mathrm{Pb}^{2+}$ at 12.5 $\mu \mathrm{g} \mathrm{L}^{-1}$ and $6.5 \mu \mathrm{g} \mathrm{L}^{-1}$ in $0.5 \mathrm{M}$ acetate buffer; deposition $E$ : $-1.3 \mathrm{~V}$; deposition time $200 \mathrm{~s}$.

during the pretreatment. After testing, the current signals were compared to analyze the influence of KI.

For optimization of the concentration of VC, different concentrations of VC solution $(3,5,10,15$, and $18 \%)$ were added to improve the performance of the method. Then, the trends of the current signals under different conditions were compared to identify the optimum concentration.

For optimization of the concentration of eluent, $5 \% \mathrm{HNO}_{3}$ and $10 \% \mathrm{HNO}_{3}$ were used as the primary eluents. The eluted liquid was prepared for detection. The concentration that gave 


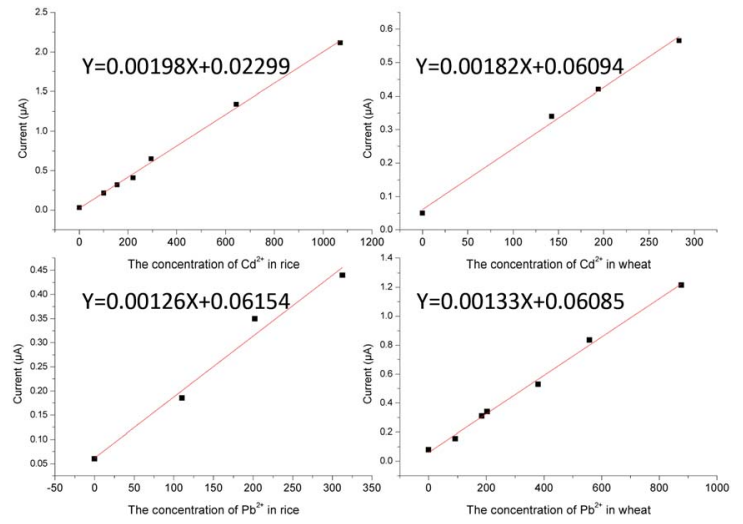

Fig. 8 The matrix-matched standard calibration curves of $\mathrm{Cd}^{2+}$ and $\mathrm{Pb}^{2+}$.

the highest current signal was selected as the appropriate concentration of the eluent.

\section{Precision and stability}

Precision was evaluated by determining the response of seven independent replicates for each sample. Furthermore, in order to perform a comprehensive evaluation, a three-person evaluation model was cited. In this model, three different concentration levels of the sample were used for analysis. The three different concentration levels were selected mainly based on the national standard limit, and high-, medium- and lowcontamination samples were selected for analysis. Each person performed the test seven times independently.

\section{Validation}

The applicability of the established method was further investigated with the certified reference materials and some real samples that were collected from different provinces of China. The sample preparation was performed according to the section "Cereal sample preparation", and the experiments were performed by the established method. In the meantime, ICP-MS measurements were carried out following a conventional procedure. Before the measurements, the samples were digested for $50 \mathrm{~min}$ by a microwave digestion procedure. And then, the results of the certified reference materials that were obtained by the established method were compared with the reported concentration values and the real sample results that were obtained by ICP-MS were compared with the results that were calculated by the established method.

\section{Results and discussion}

\section{Optimization of the sample extraction conditions}

After the pretreatment of the cereal samples, the supernatant was transferred to the cell to be detected. It was found that the peaks were not smooth and even had a slight offset. That is to say, some organic molecules, such as starch, fats, proteins, etc. caused severe interference for determination. In order to obtain a better sensitivity and stability to achieve simultaneous detection of $\mathrm{Pb}^{2+}$ and $\mathrm{Cd}^{2+}$ in this portable method on-site, some experimental conditions which may affect the extraction and current response were optimized.

\section{Optimization of the nitric acid concentration}

In order to extract $\mathrm{Cd}^{2+}$ and $\mathrm{Pb}^{2+}$ simultaneously, the concentration of acid was studied. As the data show, when the acid was at low concentrations, such as $3 \% \mathrm{HNO}_{3}$ and $5 \% \mathrm{HNO}_{3}$, the extraction rate of $\mathrm{Pb}^{2+}$ was slightly lower than using $10 \% \mathrm{HNO}_{3}$ (Fig. 2). When the concentration was increased further, the extraction rate of $\mathrm{Pb}^{2+}$ decreased gradually. This phenomenon appeared in both rice and wheat. As for $\mathrm{Cd}^{2+}$, all concentrations of diluted nitric acid that were used for extracting $\mathrm{Cd}^{2+}$ could give a recovery of approximately $100 \%$. That is to say, $\mathrm{Cd}^{2+}$ was more easily extracted by dilute acid and was more stable than $\mathrm{Pb}^{2+}$ in dilute acid solution. Therefore, considering the extraction rate of $\mathrm{Pb}^{2+}$ and the usage of $\mathrm{HNO}_{3}, 10 \% \mathrm{HNO}_{3}$ was employed in further investigations.

\section{Optimization of the ratio of sample to diluted-nitric acid $(\mathrm{m} / \mathrm{v})$}

The ratio of sample to diluted-nitric acid ( $\mathrm{m} / \mathrm{v})$ was also an important factor for extraction. Fig. 3 shows the results of the two metal ion recoveries under different ratios of sample mass to diluted-nitric acid volume. At these three ratios, there was no significant change in the extraction rate of $\mathrm{Cd}^{2+}$, whether it was rice or wheat. However, the extraction rate of $\mathrm{Pb}^{2+}$ rose with an increase in the solid-liquid ratio, and tended to be stable at $1: 10$. The highest recoveries appeared at $1: 10$ for both $\mathrm{Pb}^{2+}$ and $\mathrm{Cd}^{2+}$. That is to say, at $1: 10$, both $\mathrm{Cd}^{2+}$ and $\mathrm{Pb}^{2+}$ can achieve the best extraction effect. When the solid-liquid ratio was less than $1: 5$, the mixture was relatively viscous and it was not easy to carry out the following step. Finally, $1: 10$ was chosen for the following experiments.

\section{Optimization of the extraction time and the extraction modes}

Two kinds of extraction modes and their corresponding times were studied. The extraction efficiency of oscillation and vortexing may not be as high as that of ultrasonic extraction, but ultrasonic extraction is not suitable in this method, because it might not be convenient on-site. However, if given more time, the two modes mentioned above may also obtain a good extraction rate. For the extraction time and the extraction mode, no matter whether vortexing or oscillation, the extraction rate of $\mathrm{Cd}^{2+}$ in rice and wheat was almost $100 \%$ (ESI $\dagger$ ), illustrating that $\mathrm{Cd}^{2+}$ was very easy to extract in acid solution. This was in good agreement with the previous research. ${ }^{27}$ Unlike $\mathrm{Cd}^{2+}$, the extraction rate of $\mathrm{Pb}^{2+}$ by the oscillation extraction mode was generally higher than that by vortexing at the same time. It may be the case that the oscillation mode was more intense than the vortexing mode, which led to the sample being in full contact with the extract, so that more $\mathrm{Pb}^{2+}$ was brought out. As can be observed in Fig. 4, when the $\mathrm{Pb}^{2+}$ in wheat was extracted by vortexing for $10 \mathrm{~min}$, the recoveries of both $\mathrm{Pb}^{2+}$ and $\mathrm{Cd}^{2+}$ were the closest to $100 \%$. Therefore, these data supplied adequate evidence for a satisfactory extraction rate. 
Table 2 The precision and stability of the method for $\mathrm{Cd}^{2+}$ and $\mathrm{Pb}^{2+}$ in rice and wheat

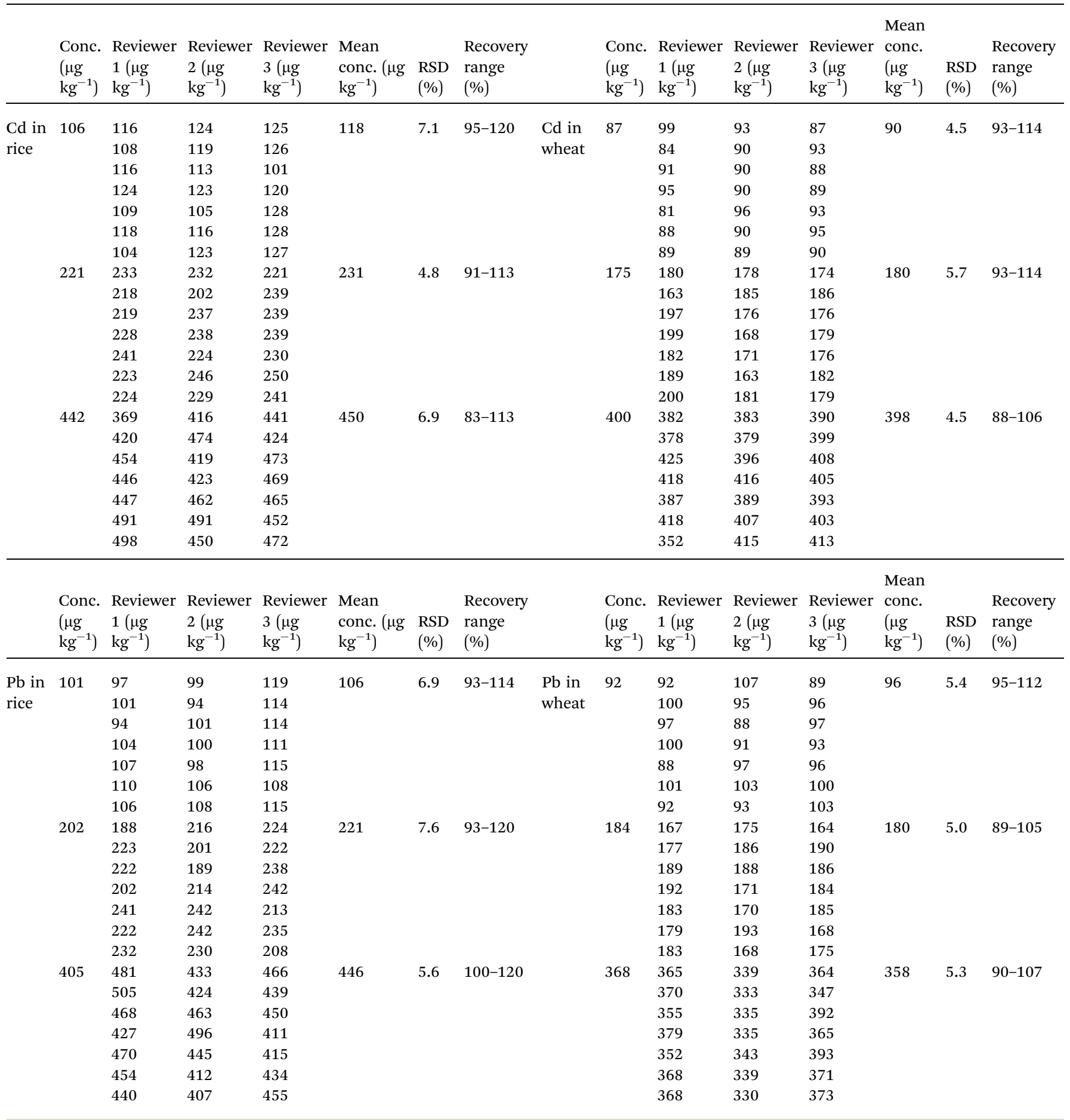

\section{Optimization of the concentration of $\mathrm{KI}$}

The main role of the $\mathrm{KI}$ is to replace the $\mathrm{Pb}^{2+}$ and $\mathrm{Cd}^{2+}$ by a displacement reaction, so that the formed $\mathrm{Pb}^{2+}$ and $\mathrm{Cd}^{2+}$ compounds are more easily dissolved in organic solvents. Some studies have reported that $\mathrm{I}^{-}$can react with $\mathrm{Cd}^{2+}$ to form $\left[\mathrm{CdI}_{4}\right]^{2-}$ under acidic conditions and $\mathrm{Pb}^{2+}$ can react with $\mathrm{I}^{-}$to form $\mathrm{PbI}_{2}$, a yellow precipitate, but this precipitate can be dissolved in excessive $\mathrm{KI}$ solution and form complex $\mathrm{K}_{2}\left[\mathrm{PbI}_{4}\right]$. The complex formed by KI and heavy metal ions was extracted by the organic phase. ${ }^{28}$ In order to determine whether residual KI could affect the electrochemical current signal, different concentrations of KI solution were added. As can be seen from Fig. 5, when testing the concentration of KI needed for electrochemical detection of $\mathrm{Cd}^{2+}$, the signal response exhibited a continuous increase until the concentration reached 
Table 3 Comparison of the results of the electrochemical method and ICP-MS for real samples

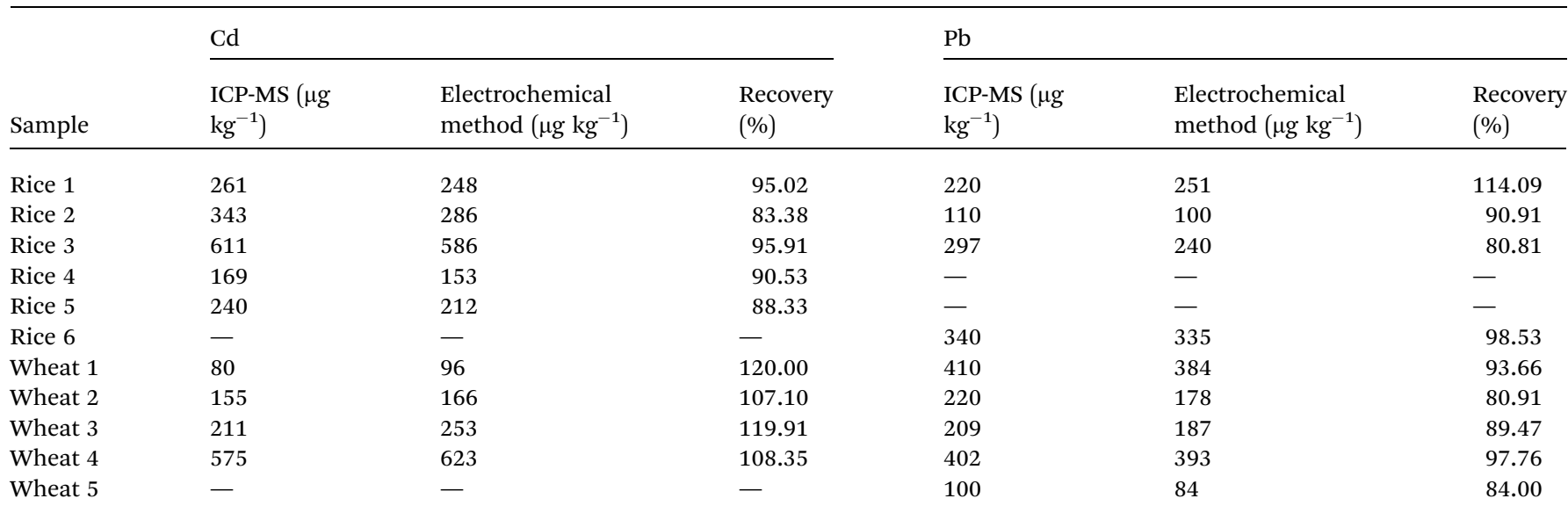

$1.0 \mathrm{~mol} \mathrm{~L}^{-1}$, and the response value showed no obvious change when the concentration was further increased. In contrast, the signal value of $\mathrm{Pb}^{2+}$ declined quickly with increasing concentration of KI until $1.0 \mathrm{~mol} \mathrm{~L}^{-1}$, and then it declined slowly as the concentration of KI kept increasing. As a compromise, $1 \mathrm{~mol} \mathrm{~L}^{-1}$ of $\mathrm{KI}$ could be beneficial for the analysis of both $\mathrm{Pb}^{2+}$ and $\mathrm{Cd}^{2+}$.

\section{Optimization of the concentration of VC}

VC is well known to be a redox-type ion masking agent that can reduce other interfering ions except for $\mathrm{Pb}^{2+}$ and $\mathrm{Cd}^{2+}$. It is reported that $\mathrm{VC}$ can reduce the oxidation of $\mathrm{KI}$ in acidic conditions. This study is performed in $\mathrm{HNO}_{3}$ and $\mathrm{HNO}_{3}$ has certain oxidation ability. Therefore $\mathrm{VC}$ is necessary to protect the function of KI. In addition, VC can also reduce some highvalence metal ions to reduce the interference in the determination. ${ }^{29}$ Besides, VC is an organic acid, which is beneficial to the reaction of $\mathrm{KI}$ and ions. Therefore, different concentrations of VC solution were added. From Fig. 6, it can be seen that the current response to $\mathrm{Cd}^{2+}$ reached the peak when the concentration of VC was $5 \%$. Meanwhile, there was no observable regularity for $\mathrm{Pb}^{2+}$. Therefore, $1 \mathrm{~mL}$ of $5 \% \mathrm{VC}$ was used for the subsequent experiments.

\section{Optimization of the concentration of eluent}

For the eluent, the concentration of the back extraction acid was a key point because it can not only affect the elution degree of $\mathrm{Pb}^{2+}$ and $\mathrm{Cd}^{2+}$ but also affect the $\mathrm{pH}$ of the electrochemical buffer to be tested. The influence is indicated in Table 1. The current response with $5 \% \mathrm{HNO}_{3}$ was much higher than that with $10 \% \mathrm{HNO}_{3}$ for $\mathrm{Cd}^{2+}$, while there were no obvious effects for $\mathrm{Pb}^{2+}$. This may be because $\mathrm{Cd}^{2+}$ was more sensitive than $\mathrm{Pb}^{2+}$ to the $\mathrm{pH}$, and although there was no significant difference in elution rate between $5 \% \mathrm{HNO}_{3}$ and $10 \% \mathrm{HNO}_{3}$, the $\mathrm{pH}$ of the electrochemical working buffer can be obviously affected. Therefore, $5 \% \mathrm{HNO}_{3}$ was chosen as the back-extraction eluent.

\section{Plotting matrix-matched calibration curves}

Under the optimum experimental conditions, matrix calibration curves of $\mathrm{Pb}^{2+}$ and $\mathrm{Cd}^{2+}$ in rice and wheat were obtained with a portable heavy metal electrochemical analyzer. The matrix effect was a ubiquitous phenomenon, and although we had eliminated the matrix effect as far as possible in the pretreatment process, there were still some disturbances left. As shown in Fig. 7, after pretreatment, the spectrum of the sample was almost the same as that of the standard solution, and there were no impurity peaks. However, the current of the sample matrix solution was slightly lower than that of the standard solution at the same concentration. It can also be seen from Fig. 7 that there was no statistical difference in the slope of the same element in the different matrices, except for the standard solutions $(p<0.05)$. More details can be found in the ESI. $\uparrow$ The reason for this phenomenon may be the inhibition phenomenon. Reagents have different intensities of inhibition on different target ions. Therefore, the most practical way to solve the matrix effect was the application of matrix-matched standard calibration, which can compensate for the response of the target in the standard solution and the sample solution to the same extent. ${ }^{30,31}$ Considering the above, the external calibration curve method was used and matrix-matched standard calibration curves of rice and wheat were plotted in this work (Fig. 8). For the instrument, we designed different matrix measurement modes, and built in a matrix standard curve corresponding to different matrices. The correlation coefficients were 0.9983 and 0.9980 for $\mathrm{Cd}^{2+}$ in rice and wheat, respectively. And the correlation coefficients were 0.9984 and 0.9962 for $\mathrm{Pb}^{2+}$ in rice and wheat, respectively. The linearity between the current signal response and the concentration of $\mathrm{Cd}^{2+}$ and $\mathrm{Pb}^{2+}$ was good in the range of the common concentration range in samples. In practice, the LOD of $\mathrm{Cd}^{2+}$ in rice and wheat can be calculated as $6.10 \mu \mathrm{g} \mathrm{kg}{ }^{-1}$ and $9.38 \mu \mathrm{g} \mathrm{kg}{ }^{-1}$, and the LOD of $\mathrm{Pb}^{2+}$ in rice and wheat can be calculated as $34.9 \mu \mathrm{g} \mathrm{kg}{ }^{-1}$ and $31.1 \mu \mathrm{g} \mathrm{kg}{ }^{-1}$, respectively. The LOQ of $\mathrm{Cd}^{2+}$ in rice and wheat was $20.33 \mu \mathrm{g}$ $\mathrm{kg}^{-1}$ and $31.25 \mu \mathrm{g} \mathrm{kg}^{-1}$, and the LOQ of $\mathrm{Pb}^{2+}$ in rice and wheat was $116.4 \mu \mathrm{g} \mathrm{kg}^{-1}$ and $103.7 \mu \mathrm{g} \mathrm{kg}^{-1}$. Compared with the analytical performance of other electrode methods that have 
been published recently, this developed method showed a consistent sensitivity and low detection limit, ${ }^{32-34}$ with no need for pre-concentration performed using a digestion procedure.

\section{Precision and stability}

Precision was evaluated by determining one sample for seven replicates. RSD was less than $8.7 \%$ for $\mathrm{Cd}^{2+}$ and $\mathrm{Pb}^{2+}$. Furthermore, in the three-person evaluation model, standard materials that contained $\mathrm{Cd}^{2+}$ and $\mathrm{Pb}^{2+}$ at $100( \pm 15 \%) \mu \mathrm{g} \mathrm{kg}{ }^{-1}, 200$ $( \pm 15 \%) \mu \mathrm{g} \mathrm{kg}{ }^{-1}$ and $400( \pm 15 \%) \mu \mathrm{g} \mathrm{kg}{ }^{-1}$ were analyzed. Each person tested one sample seven times independently. The results are shown in Table 2 with recoveries between $83 \%$ and $120 \%$ and RSDs less than $8 \%$. These data indicated that the method had good reproducibility.

\section{Application to analysis of cereal samples}

The practical applicability of the established method was further investigated with a real sample test. Sample preparation was performed according to the "Cereal sample preparation" section, and the following experiment was performed by the established method. The results were compared with ICP-MS to obtain a relative recovery. Table 3 shows satisfactory recovery results of $80-120 \%$ for both $\mathrm{Pb}^{2+}$ and $\mathrm{Cd}^{2+}$, and the results confirmed that the developed method has good availability.

\section{Conclusions}

In summary, a rapid method for the detection and determination of $\mathrm{Cd}^{2+}$ and $\mathrm{Pb}^{2+}$ in rice and wheat based on electrochemical analysis with disposable screen-printed electrodes was established. The important sample pretreatment for the extraction and purification of the targeted ions was optimized and developed. With the optimal conditions, the electrochemical platform exhibited acceptable stability and reproducibility, and good portability. The present study demonstrated the excellent and practical potential of this method for the simultaneous determination of $\mathrm{Cd}^{2+}$ and $\mathrm{Pb}^{2+}$ in situ, with the obvious advantages of simplicity, high speed, and high sensitivity. Moreover, the whole process of highthroughput analysis could be completed in $25 \mathrm{~min}$ with a relatively low cost, which is especially suitable for high-throughput analysis. The electrochemical platform also exhibited acceptable stability and reproducibility, and good portability, which are of great importance for screening $\mathrm{Pb}^{2+}$ and $\mathrm{Cd}^{2+}$ in cereals on-site. Therefore, the method that we have developed is acceptable to monitor $\mathrm{Pb}^{2+}$ and $\mathrm{Cd}^{2+}$ simultaneously in cereal samples on-site.

\section{Conflicts of interest}

There are no conflicts to declare.

\section{Acknowledgements}

This study was funded by The National Key Research and Development Program of China and the Research Project of the
National Special Project for Key Science and Technology of Food Safety (Grant No. 2017YFC1601300), and the Special Fund for Basic Research Business Expenses of Central-level Public Welfare Research Institutes (Grant No. ZX1913).

\section{References}

1 M. B. Gumpu, S. Sethuraman, U. M. Krishnan and J. B. B. Rayappan, Sens. Actuators, B, 2015, 213, 515.

2 B. Sharma, S. Singh and N. J. Siddiqi, BioMed Res. Int., 2014, 2014, 1.

3 B. Chouhan, P. Meena and N. Poonar, J. Sci. Eng. Res., 2016, 4(4), 2015.

4 B. K. Bansod, T. Kumar, R. Thakur, S. Rana and I. Singh, Biosens. Bioelectron., 2017, 94, 443.

5 I. M. Chung, J. K. Kim, K. J. Lee, S. K. Park, J. H. Lee, N. Y. Son, Y. I. Jin and S. H. Kim, Food Chem., 2018, 240, 840. 6 S. Li, C. Zhang, S. Wang, Q. Liu, H. Feng, X. Ma and J. Guo, Analyst, 2018, 143, 4230.

7 R. M. de Oliveira, A. C. N. Antunes, M. A. Vieira, A. L. Medina and A. S. Ribeiro, Microchem. J., 2016, 124, 402.

8 X. Liu, F. Suo, M. He, B. Chen and B. Hu, Microchim. Acta, 2017, 184, 927.

9 M. A. Almessiere, R. Altuwiriqi, M. A. Gondal, R. K. AlDakheel and H. F. Alotaibi, Talanta, 2018, 185, 61.

10 E. J. Sneddon, C. J. Hardaway, J. Sneddon, K. Boggavarapu, A. S. Tate, S. L. Tidwell, D. P. Gary and C. Douvris, Microchem. J., 2017, 134, 9.

11 M. Lv, Y. Liu, J. Geng, X. Kou, Z. Xin and D. Yang, Biosens. Bioelectron., 2018, 106, 122.

12 G. Zhao, H. Wang, G. Liu, Z. Wang and J. Cheng, Ionics, 2017, 23, 767.

13 A. García-Miranda Ferrari, C. W. Foster, P. J. Kelly, D. A. C. Brownson and C. E. Banks, Biosensors, 2018, 8, 1.

14 B. Molinero-Abad, D. Izquierdo, L. Pérez, I. Escudero and M. J. Arcos-Martínez, Talanta, 2018, 182, 549.

15 L. F. Ribeiro and J. C. Masini, Talanta, 2018, 185, 387.

16 G. M. S. Alves, L. S. Rocha and H. M. V. M. Soares, Talanta, 2017, 175, 53.

17 R. Rapini and G. Marrazza, Bioelectrochemistry, 2017, 118, 47. 18 X. Zhang, Y. Zhang, D. Ding, J. Zhao, J. Liu, W. Yang and K. Qu, Microchem. J., 2016, 126, 280.

19 G. Zhao, Y. Yin, H. Wang, G. Liu and Z. Wang, Electrochim. Acta, 2016, 220, 267.

20 J. Terán-Baamonde, R. M. Soto-Ferreiro, A. Carlosena, J. M. Andrade and D. Prada, Talanta, 2018, 186, 272.

21 H. Wang, T. Jiang, Y. Tang, Y. Zou and T. Jiang, Food Sci., 2014, 35, 88.

22 J. S. De Gois, I. O. Lucena, P. S. D. O. Cezario, A. P. Da Silva, I. C. A. Lima and A. S. Luna, Anal. Methods, 2018, 10, 1656.

23 Y. Shi and A. Chatt, J. Radioanal. Nucl. Chem., 2014, 299, 867. 24 W. Xin, Chin. J. Spectrosc. Lab., 2008, 25, 705.

25 A. C. C. Rodrigues and J. L. F. Monteiro, Appl. Catal., A, 2009, 362, 185.

26 M. Zhou, S. Wang and Y. Wu, Chin. J. Anal. Chem., 2014, 42, 459. 
27 M. Zhou, Y. Wu, J. Zhang, Y. Zhang, X. Chen, J. Ye and S. Wang, Anal. Sci., 2019, 35, 283.

28 N. Meeravali, R. Manjusha, K. Madhavi and S. Kumar, Desalin. Water Treat., 2016, 57, 26880.

29 A. M. D. S. Chandrathilaka, O. A. Heperuma and C. V. Hettiarachchi, J. Natl. Sci. Found. Sri Lanka, 2013, 41, 337.

30 Analytical Chemistry Division, Spectrochim. Acta, Part B, 1978, 33, 241.
31 J. Zrostlıkova and J. Hajslova, J. Chromatogr. A, 2003, 1000, 181.

32 W. Siriangkhawut, P. Sittichan, K. Ponhong and P. Chantiratikul, J. Food Compos. Anal., 2017, 59, 145.

33 H. J. Kim, D. W. Son, J. M. Park, D. Y. Hwang, C. Y. Mo, S. W. Park, G. Kim and J. B. Eun, Food Sci. Biotechnol., 2010, 19, 1211.

34 K. Keawkim, S. Chuanuwatanakul, O. Chailapakul and S. Motomizu, Food Control, 2013, 31, 14. 